\title{
Use of distant V-Y plasty in reconstruction of defects on the nasal dorsum: A new modification of V-Y plasty
}

\author{
Ibrahim Askar $\mathrm{MD}^{1}, \mathrm{M}$ Faruk Oktay $\mathrm{MD}^{2}$
}

\begin{abstract}
I Askar, MF Oktay. Use of distant V-Y plasty in reconstruction of defects on the nasal dorsum: A new modification of V-Y plasty. Can J Plast Surg 2003;11(4):219-223.

Nasal reconstruction requires a good aesthetic outcome because the nose is located in the centre of the face. Two problems commonly occur after reconstruction of the nose: abnormal appearance of the new nose, and nasal airway obstruction. The nasal dorsum should be treated as a separate unit. Several local flaps have been described for reconstruction of tissue defects on the dorsum of the nose. Most of these techniques have some disadvantages, such as colour mismatch, dog-ear formation, thickness of flaps and requirement of surgery for revision. Two patients in whom the nasal dorsum was reconstructed with distant V-Y plasty are presented. Six months later, cosmetically acceptable results were obtained. The authors believe that the distant $\mathrm{V}$-Y plasty is an effective alternative to the current techniques in reconstruction of the nasal dorsum. The advantages of this technique include the following: distant V-Y plasty is a safe and useful way to reconstruct medium and large defects of the nasal dorsum; it provides good texture and colour match; the resultant scar cannot cause contour deformity because it is not a bulky flap; there are no formation of dog-ear; it can be used to cover larger defects in elderly patients; it can be used under local anesthesia in almost all cases; it requires a shorter period of operating time and hospitalization; and it is less costly.
\end{abstract}

Key Words: Distant V-Y plasty; Medium and large defects; Nasal dorsum

$\mathrm{N}$ asal reconstruction requires a good aesthetic outcome because the nose is located in the centre of the face. Two problems commonly occur after reconstruction of the nose: abnormal appearance of the new nose, and nasal airway obstruction. The appearance of a reconstructed nose is dependent on its colour, texture and contour. Colour and texture are related to the choice of donor area. Consequently, a limited choice of donor areas is available for nasal skin cover (Table 1) (1). Several skin flaps have been developed to reconstruct defects involving different regions of the nose.

Burget and Menick (2) and Yotsuyanagi et al (3) treated the nasal dorsum and other regions of the nose as separate units. Various local flaps have been described for reconstruction of tissue defects on the dorsum of the nose. These flaps originate from the nasolabial sulcus, glabella, forehead and malar area. Burget and Menick treated the nasal dorsum and side walls separately, and used cheek advancement flaps in the

\section{Plastie par lambeau en VY à distance pour la reconstruction du dos du nez : technique modifiée}

La reconstruction du nez exige de bons résultats sur le plan de l'esthétique étant donné que le nez se trouve au centre de la face. Toutefois, l'opération donne souvent lieu à deux types de problème : l'apparence anormale du nouveau nez et l'obstruction des voies nasales. Il faudrait que le dos du nez soit traité comme une entité distincte. Il existe plusieurs techniques de plastie par lambeau de voisinage pour la reconstruction du dos du nez, mais la plupart comportent des désavantages comme la différence de couleur, la formation de bourgeons, l'épaisseur des lambeaux et la nécessité de recourir à la chirurgie pour les reprises. Voici deux cas de reconstruction du dos du nez par lambeau en VY à distance, qui a donné, au bout de six mois, des résultats acceptables du point de vue esthétique. Les auteurs sont d'avis que la plastie par lambeau en VY à distance constitue une bonne solution de rechange aux techniques actuelles de reconstruction du dos du nez. En effet, la nouvelle technique offre plusieurs avantages, notamment son innocuité et ses possibilités de reconstruction de parties relativement grandes du dos du nez, sa texture et l'absence de différence de couleur, la non-déformation du contour par la cicatrice en raison de l'utilisation de lambeaux plutôt minces, l'absence de formation de bourgeons et sa capacité de couvrir de grandes surfaces chez les personnes âgées. De plus, elle peut être pratiquée sous anesthésie locale dans la plupart des cas, elle nécessite un temps d'intervention moins long et un séjour plus court à l'hôpital et elle coûte moins cher que les autres techniques. 


\section{TABLE 1}

Reconstructive options for nasal skin cover

\begin{tabular}{ll}
\hline Defect & Preferred option for skin cover \\
\hline Defect $\leq 5 \mathrm{~mm}$ & Direct closure \\
Defect $\leq 5 \mathrm{~mm}$ in the alar margin and soft triangles & Composite auricular helix graft \\
Defect $\leq 1.5 \mathrm{~cm}$ in the upper two-thirds of the nose & Simple transposition flap \\
Defect $\leq 1.5 \mathrm{~cm}$ in the thick-skinned zones of the nose (tip, supratip and alae) & Bilobed flap of Zitelli design \\
Defect between $1.5 \mathrm{~cm}$ and $2 \mathrm{~cm}$ in the upper two-thirds of the nose & Full-thickness preauricular skin graft \\
Massive defect involving any or all parts of the nose & Axial paramedian forehead flap based on unilateral supratrochlear artery \\
Isolated defect of the alar lobule subunit & Superiorly based nasolabial flap on subcutaneous pedicle
\end{tabular}

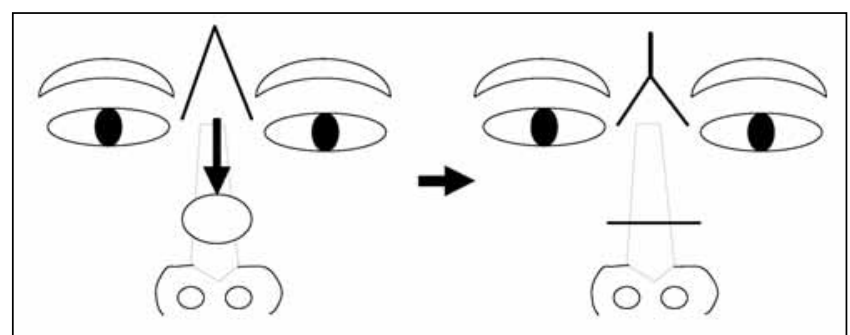

Figure 1) Incisions in the glabella were designed to reconstruct the lower portion of the nasal dorsum. The angle between two incisions was adjusted according to the size of the defect in the lower portion of the nasal dorsum. Incisions were equal in length. The V-flap was undermined down to the defect area (dotted area). Then, the V-flap was advanced downward to cover the defect (in the direction of the arrow). The donor area was sutured primarily in the glabella.

\section{SURGICAL TECHNIQUE}

Incisions were designed in the glabella to reconstruct a medium or large defect in the lower portion of the nasal dorsum. The angle between two incisions was adjusted according to the defect size in the lower portion of the nasal dorsum. Incisions were equal in length (Figure 1). The V flap was undermined down to the defect area and laterally to the nasal sidewalls, and fibrotic bands were released if they were present. Then, the $\mathrm{V}$ flap was advanced downward to cover the defect. The donor area was sutured primarily in the glabella.

\section{CASE PRESENTATIONS}

\section{Case 1}

A 45-year-old man suffering from a postburn scar contracture was admitted to the plastic surgery clinic at the Dicle Unversity medical school. Physical examination revealed a transverse postburn scar contracture localized on the dorsum of the nose (Figure 2). The postburn scar contracture was released, and the resultant round tissue defect was $25 \mathrm{~mm}$ in diameter. A distant V-Y plasty from the glabella was planned to repair the tissue defect (Figure 3). The $\mathrm{V}$ flap extended down to the defect area and laterally to the nasal sidewalls. The tissue defect and donor area of flap were closed primarily (Figure 4). Six months later, the result was cosmetically acceptable (Figure 5).

\section{Case 2}

A 56-year-old woman had been suffering from an ulcer on her nasal dorsum for two years. Physical examination showed an ulcerative lesion, $20 \mathrm{~mm}$ in diameter with surrounding hyperemia

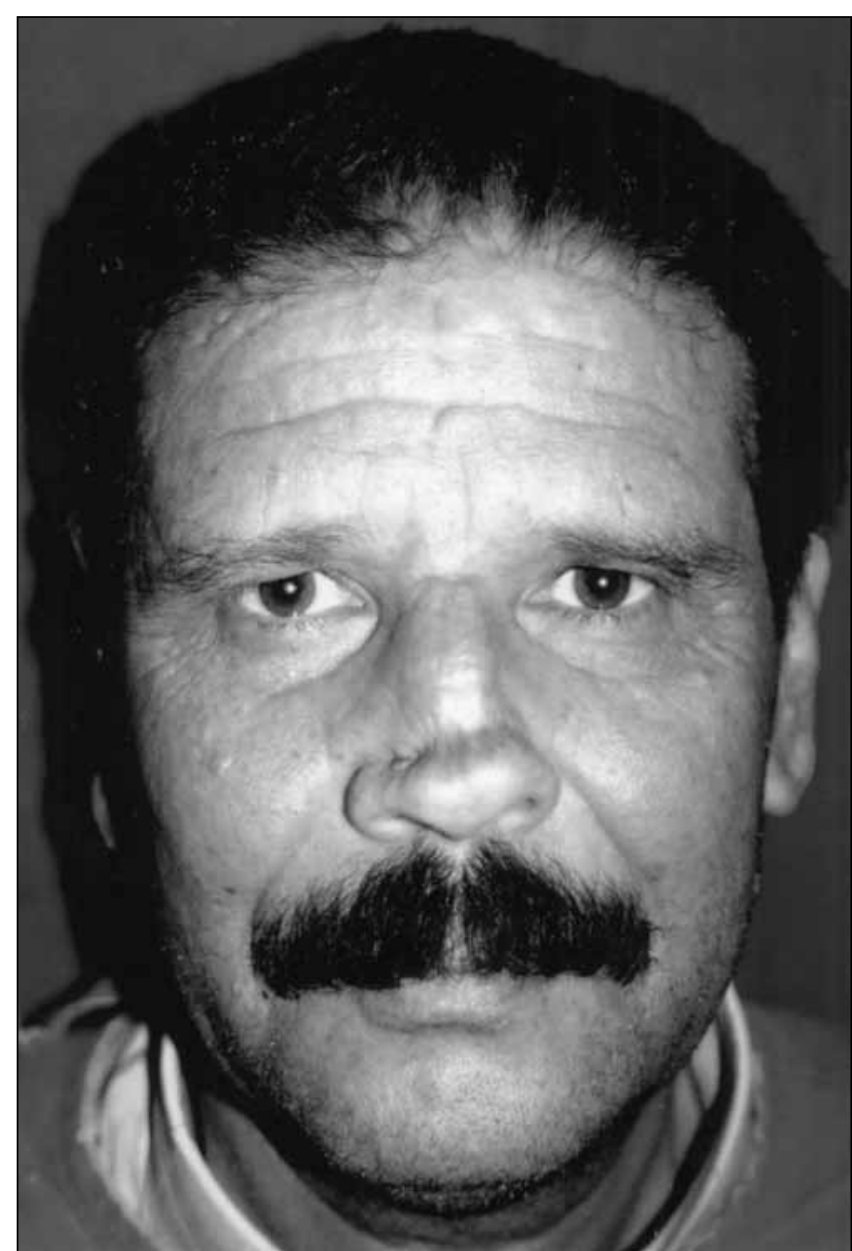

Figure 2) A 45-year-old man suffering from a postburn scar contracture on the nasal dorsum

on the nasal dorsum (Figure 6). Treating the lesion as a basal cell carcinoma, the lesion was excised with a safety margin of $5 \mathrm{~mm}$, leading to a tissue defect $30 \mathrm{~mm}$ in diameter. The resultant defect was repaired with a distant V-Y plasty from the glabella. A cosmetically acceptable scar was obtained six months later (Figure 7).

\section{DISCUSSION}

Burget and Menick (2) and Millard (4) stated four factors affecting the outcome of nasal reconstruction: good contrast between the nose and its surroundings; an inconspicuous border scar; a good colour and texture match with the surrounding 


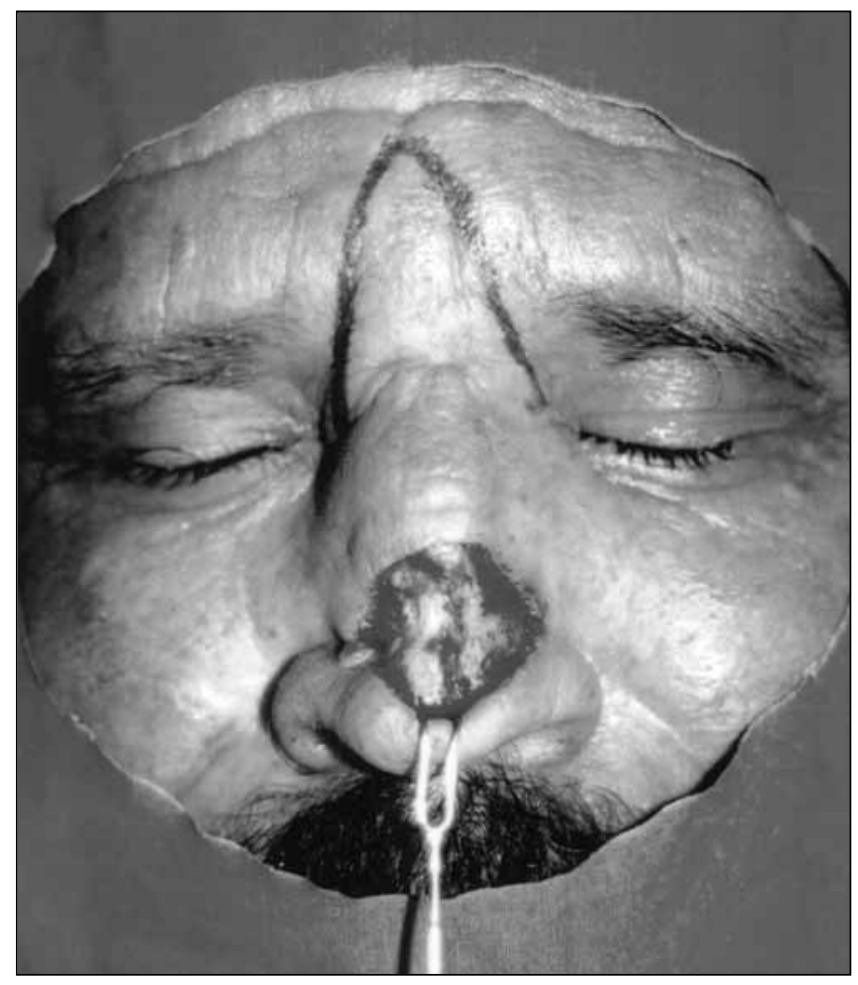

Figure 3) A distant V-Y plasty was planned from the glabella to the resultant tissue defect

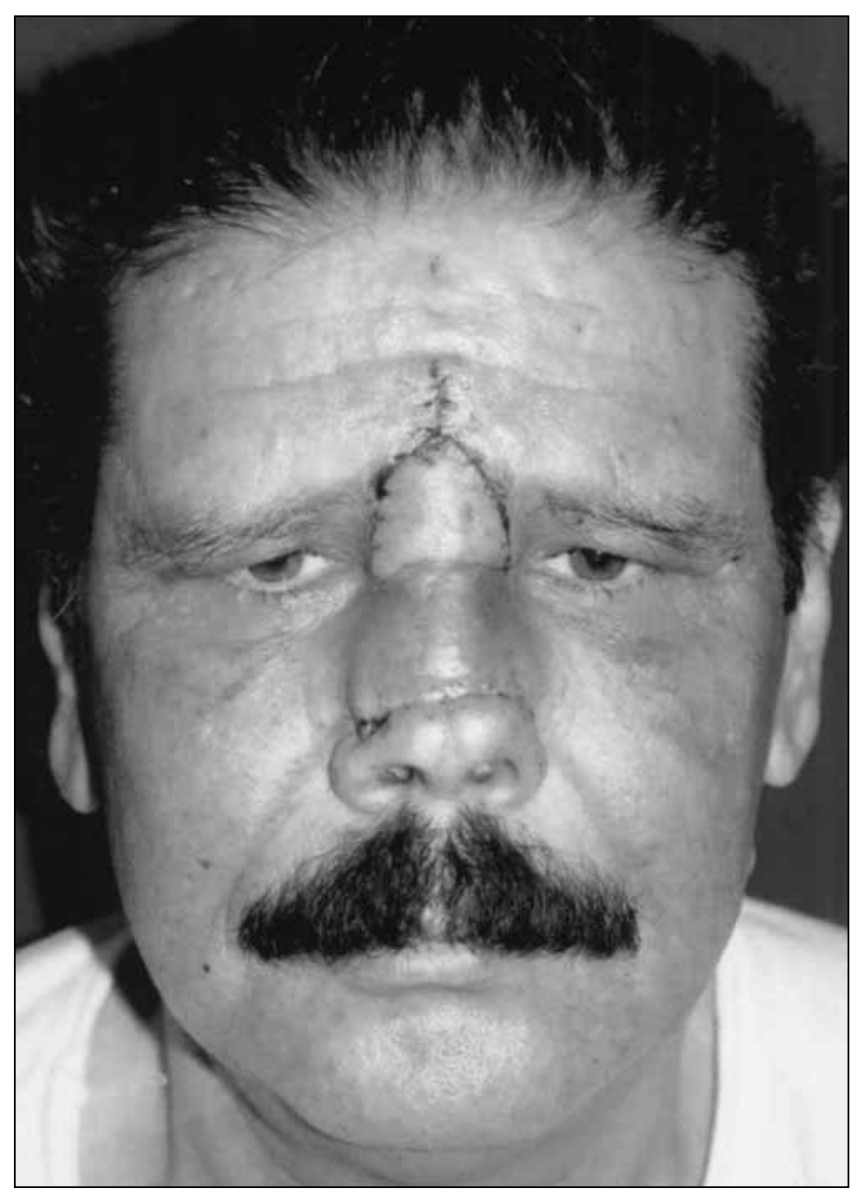

Figure 4) The tissue defect and donor area were closed primarily

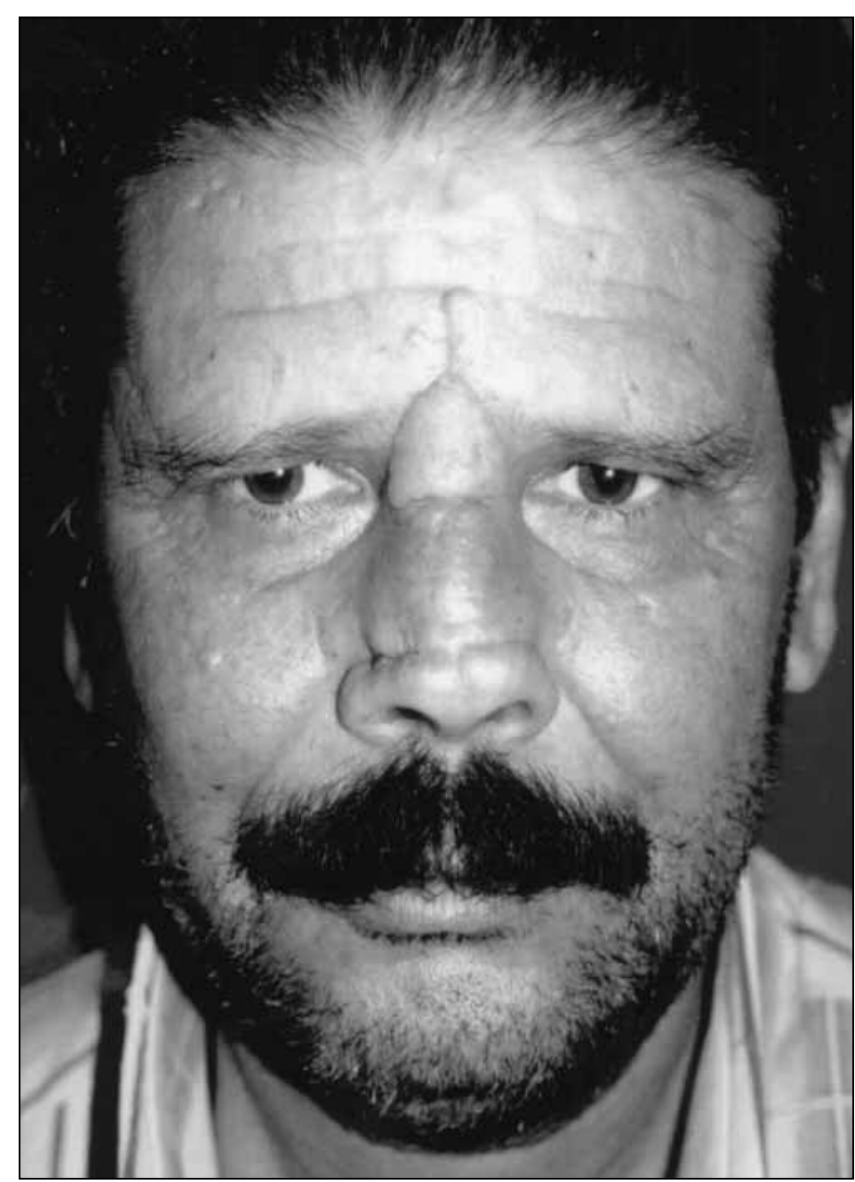

Figure 5) The postoperative result was cosmetically acceptable six months after the distant V-Y plasty

skin; and bilateral symmetry. The surgical procedure used should best fulfill the requirements of the patient. Small defects are usually repaired with Limberg flaps, subcutaneous pedicled flaps, or frontonasal flaps developed from the adjoining skin (6-12). In medium and large defects, it is more difficult to achieve a good match of skin texture and colour. A good aesthetic outcome of reconstruction needs adequate contrast with the surrounding facial features and an inconspicuous border scar. The aesthetic subunits of the nose are designed to achieve these objectives (2). A forehead flap is used for reconstruction of the nasal dorsum, glabella and nasal tip. In addition, a nasolabial flap is used for alar reconstruction and a malar flap is used to reconstruct the cheek $(5,12,13)$. However, there is still debate about the ideal flap. For example, the forehead flap may require grafting of the donor area, it may lead to trapdoor contraction, it may cause congestion or necrosis, and it may require tissue expanders to reach the lowermost part of the nose $(3,4)$. In our study, distant $\mathrm{V}-\mathrm{Y}$ plasty was easily used in the repair of medium and large defects of the nasal dorsum. In elderly patients, distant V-Y plasty can be used to repair a larger defect than that of the young patients, because the laxity of skin is increased in the elderly.

The V-Y plasty was probably first described by Ernst Blasius (14). He used V-Y plasty for the correction of a contracted burn scar of the neck. The recent classification of V-Y plasty and its analogs was proposed by Suzuki et al (15): Y-V plasty 


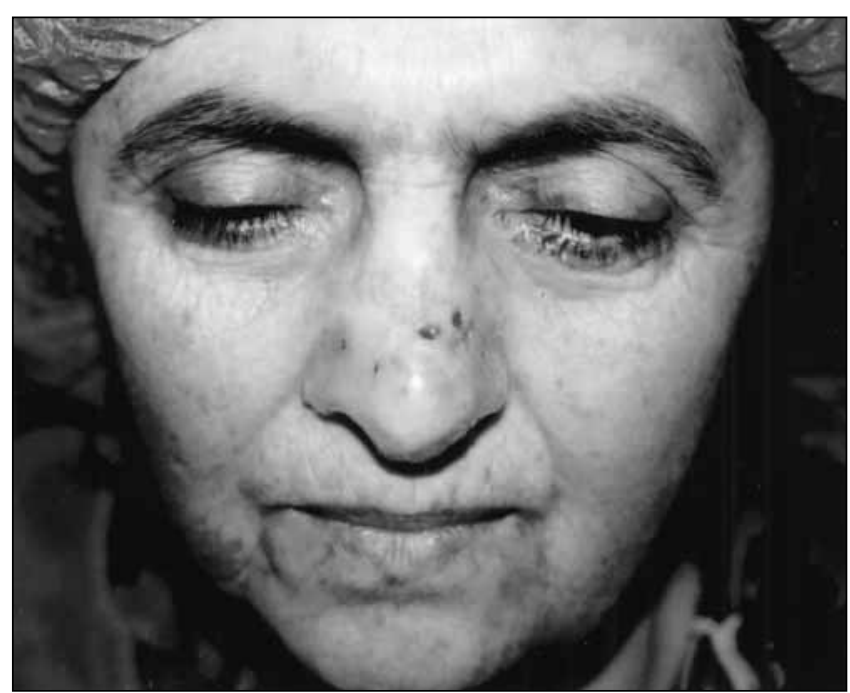

Figure 6) A 56-year-old woman with an ulcerative lesion on the nasal dorsum

(Y-V plasty with Burow's triangles, Y-V plasty with inverted Burow's triangles, five- $Z$ plasty and their combinations), and double Y-V plasty (VW plasty, VM plasty, seven-Z plasty and their combinations). Suzuki et al suggested that extra tissue is produced in the original V-Y plasty after the $\mathrm{V}$ flap is advanced in the original V-Y plasty, because the lateral skin border of the $\mathrm{V}$ flap is shorter than the total length of the Y. Limberg preferred to use a pair of Burow's triangle excisions on each side (15).

The distant V-Y plasty consists of only one V-Y plasty. Actually, distant V-Y plasty is a combination of bipedicled flap and V-Y plasty. Moreover, careful planning of distant V-Y plasty requires no Burow's triangle excision. In the distant V-Y plasty, the $\mathrm{V}$ flap is undermined to advance inferiorly to cover defects on nasal dorsum. It is nourished by each side of the nose so it survives like a bipedicled flap. The distant V-Y plasty transfers less tissue from the donor area than the forehead flap. Both increase the survival of the distant V-Y plasty more than that of a forehead flap. The distant V-Y plasty supports texture and colour matching, and it does not cause contour deformity, because it is not bulky.

Yotsuyanagi et al (3) recommended a subcutaneous pedicled flap with a V-Y advancement design in patients with small defects. However, in our study, distant V-Y plasty was used in repair of medium and large defects in the nasal dorsum. There was no evidence of contour deformity, texture or colour mismatch in either patient.

Because it requires fewer incisions than other techniques, distant V-Y plasty allows us to perform the operation under

\section{REFERENCES}

1. Burget GC, Burget DE Jr. Reoperative surgery for nasal reconstruction. In: Grotting JC, ed. Reoperative Aesthetic \& Reconstructive Plastic Surgery, Vol I. St Louis: Quality Medical Publishing, Inc, 1995:511-58.

2. Burget GC, Menick FJ. The subunit principle in nasal reconstruction. Plast Reconstr Surg 1985;76:239-47.

3. Yotsuyanagi T, Yamashita K, Urushidate S, Yokoi K, Sawada Y. Nasal reconstruction based on aesthetic subunits in orientals. Plast Reconstr Surg 2000;106:36-44.

4. Millard DR Jr. Reconstructive rhinoplasty for the lower two-thirds of the nose. Plast Reconstr Surg 1976;57:722-8.

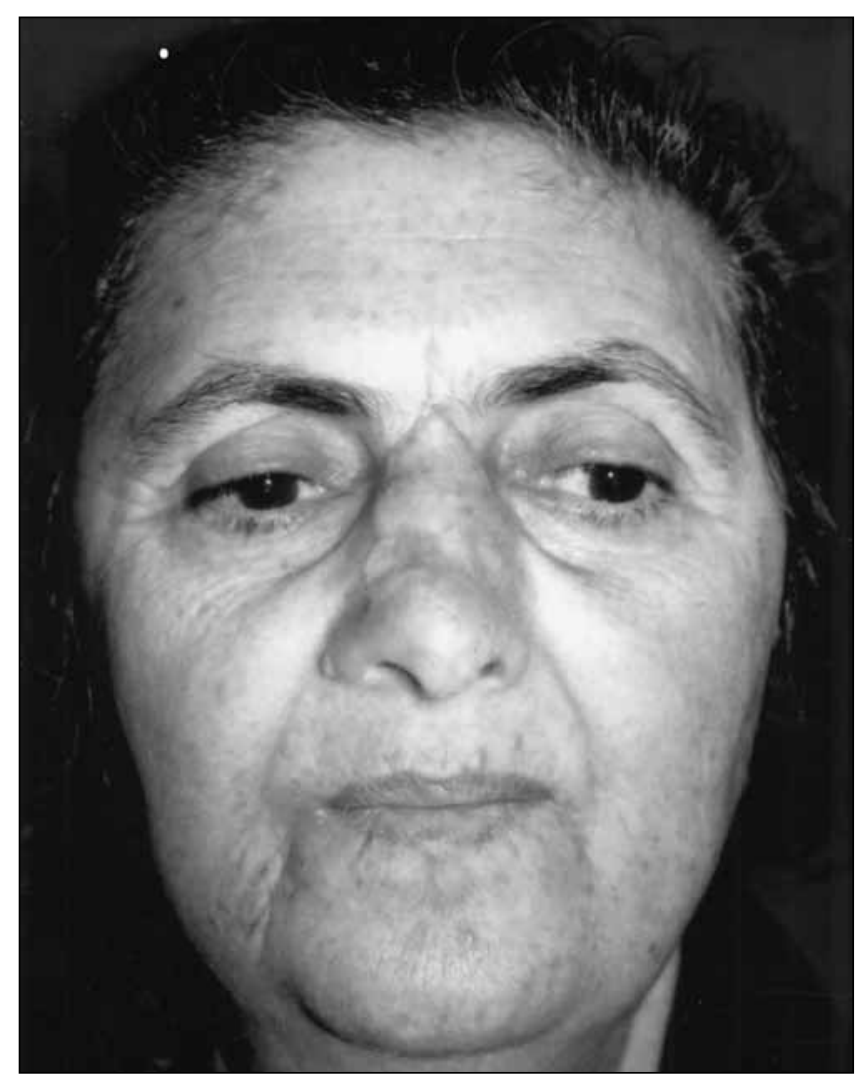

Figure 7) A cosmetically acceptable scar was obtained six months after the distant V-Y plasty

local anesthesia in most cases, and requires a shorter period of operating time than other techniques. Larger flaps may be used in elderly patients, due to their increased skin laxity. As a result of these advantages, V-Y plasty has less morbidity, a shorter hospitalization period, and is less costly.

\section{CONCLUSIONS}

Distant V-Y plasty is an effective alternative to the current techniques in reconstruction of the nasal dorsum. The advantages of this technique are as follows: distant V-Y plasty is a safe, useful technique for reconstructing medium and large defects of the nasal dorsum; it provides good texture and colour match; the resultant scar does not cause contour deformity because it is not a bulky flap; there is no formation of dog-ear; larger amounts of skin can be elevated in elderly patients; it can be used under local anesthesia in almost all cases; it requires a shorter period of operating time and hospitalization; and it is less costly.

5. Ogino Y. The technical advances in the reconstructive rhinoplasty. In: Meyers E, ed. New Dimensions in Oto-Rhino-Laryngology: Head and Neck Surgery, Vol 1. Amsterdam: Excerpta Medica, 1985:619-22.

6. Doermann A, Hauter D, Zook EG, Russell RC. V-Y advancement flaps for closure of nasal defects. Plast Reconstr Surg 1989;84:916-20.

7. Strauch B, Fox M. V-Y bipedicle flap for resurfacing the nasal supratip region. Plast Reconstr Surg 1989;83:899-903.

8. Marchac D, Toth B. The axial frontonasal flap revisited. Plast Reconstr Surg 1985;76:686-94. 
9. de Fontaine S, Klaassen M, Soutar DS. Refinements in the axial frontonasal flap. Br J Plast Surg 1993;46:371-4.

10. Maruyama Y, Iwahira Y. The axial nasodorsum flap. Plast Reconstr Surg 1997;99:1873-7.

11. Herbert DC. A subcutaneous pedicled cheek flap for reconstruction of alar defects. Br J Plast Surg 1978;31:79-92.

12. Uchinuma E, Matsui K, Shimakura Y, Murashita K, Shioya N. Evaluation of the median forehead flap and the nasolabial flap in nasal reconstruction. Aesth Plast Surg 1997;21:86-9.
13. Barton FE, Byrd HS. Acquired deformities of the nose. In: Plastic Surgery, Vol 3. Philadelphia: Saunder, 1990:1925-2008.

14. Hauben DJ. Ernst Blasius's contributions to plastic surgery. Plast Reconstr Surg 1984;74:561-70.

15. Suzuki S, Matsuda K, Nishimura Y. Proposal for a new comprehensive classification of V-Y-plasty and its analogues: The pros and cons of inverted versus ordinary Burow's triangle excision. Plast Reconstr Surg 1996;98:1016-22. 